\section{Questión}

Periodismo / Comunicación ISSN 1669-6581
- Av. $44 \mathrm{~N}^{\circ} 676,1^{\circ}$ piso

CP 1900 - La Plata - Argentina

www.perio.unlp.edu.ar/question

Puerto Rico, Covid-19 y el baile de la corrupción

Eliseo R. Colón Zayas

DOI: https://doi.org/10.24215/16696581e298

\title{
Puerto Rico, Covid-19 y el baile de la corrupción
}

\section{Puerto Rico, Covid-19 and the dance of corruption}

Eliseo R. Colón Zayas / eliseo.colon@upr.edu Nacido en Puerto Rico (1956) es catedrático, investigador y profesor de Semiótica, Comunicación y Estética, Discurso Publicitario y Estudios Culturales, en la Escuela de Comunicación de la Universidad de Puerto Rico. Es autor además de varios libros sobre temas de su especialidad, así como de artículos y ensayos sobre temática comunicacional y cultura, publicados en revistas especializadas y periódicos.

Un tranquilo y soleado domingo con las playas llenas, los centros comerciales abarrotados, las salas de cines con sus estrenos y las familias apresurando reuniones festivas, la propagación global del Covid -19 se convirtió en Puerto Rico en asunto público y el estado intervino. Era un domingo, 15 de marzo, como muchos otros hasta que el asunto de estado devino pándêmos (pan [todos] demus [pueblo]). Es decir, el estado gritó pandemia y la señora Wanda Vázquez, gobernadora de un territorio que le pertenece a Estados Unidos, pero no es parte suya, Puerto Ricoi, cerró a cal y canto la isla (menos su aeropuerto) mediante una orden ejecutiva. La gobernadora había decretado el 12 de marzo un estado de emergencia para promover el confinamiento ciudadano. El 15 de marzo ordenó un toque de queda aplicable a toda la ciudadanía desde las $21 \mathrm{hrs}$ de la noche hasta las $5 \mathrm{hrs}$ de la madrugada y el cierre completo de las empresas e instituciones públicas y privadas, excepto supermercados, farmacias, restaurantes con servicio a domicilio, empresas de equipo médico, gasolineras y proveedores de estos comercios. Con el toque de queda, comenzó el tiempo del teletrabajo en las empresas privadas y públicas y la enseñanza a través de Internet en las escuelas y universidades. 
La orden ejecutiva del 15 de marzo extendía el cierre inicial hasta el 30 de marzo. Posteriormente, las fechas para levantar el confinamiento, el cierre y el toque de queda se han ido modificando, primero al 12 de abril y luego al 4 de mayo. La gobernadora formó dos grupos de asesores, un task-force sanitario y un task-force económico, cuyos criterios supuestamente refuerzan la política pública para atender la propagación del Covid 19 en la isla. Por otro lado, la gobernadora estableció el 30 de marzo las directrices de vigilancia, control y cuarentena de todos los pasajeros que aterrizaban en el aeropuerto internacional Luis Muñoz Marín, a la vez que cerraba todos los otros aeropuertos de la isla.

Hay dos fuentes de información oficiales que indican las cifras en el número de muertos y contagiados por el Covid 19. El portal del Departamento de Saludo de Puerto Rico ha abierto un portal informativo al público en Internet que ofrece información diaria sobre el número de fallecidos y contagiados, e información sobre los hospitales.ii El portal incluye una visualización donde se puede obtener información por región y por pueblo.iii Asimismo, el Instituto de Estadísticas de Puerto Rico ofrece datos importantes en torno a los casos positivos acumulados, la curva epidémica, el factor de crecimiento diario, características demográficas.iv Más allá de agarrarse a los discursos y a las cifras oficiales, la tensión, la ansiedad y la incertidumbre del confinamiento pandémico causado por del flujo viral del Covid - 19 ha llevado a gran parte de la población de Puerto Rico a buscar certezas en opiniones, noticias de la radio, televisión, periódicos e Internet, a entrevistas, a crónicas, a lecturas, recuentos, cifras, consejos, Memes, Influencers, YouTubers, vídeos, películas, series, Twitter, publicaciones de Facebook, fotografías de Instagram, chats en WhatsApp. En un país como Puerto Rico, cuya población es de 3,2 millones de habitantes en un territorio de $13.800 \mathrm{~km}^{2}$ y donde al 26 de marzo se habían registrado 84 muertos por el Covid -19 y 1.371 casos positivos, el evento mediático y la teatralización y escenificación ritual de la política en los medios de comunicación en los tiempos del confinamiento y del Coronavirus no ha sido alrededor del virus, su prevención y efectos, sino que han estado marcados por la información sobre los actos de corrupción gubernamental presentes durante todo el estado de emergencia. El gobierno de Puerto Rico ha fracasado en el manejo de la crisis del Covid -19. La corrupción que ha marcado en todo momento al partido en el poder y que llevó el verano de 2019 a la ciudadanía a salir a la calle y lograr la renuncia del entonces gobernador ha sido el tema central durante todo el periodo del estado de emergencia y confinamiento de la población. El gobierno y los 
miembros del task-force médico hicieron negocios inescrupulosos con empresarios vinculados al Partido Nuevo Progresista, el partido en el poder, para comprar el material sanitario necesario para comenzar a hacer las pruebas del Covid-19 a precios exorbitantes y nada sirvió. A la crisis de la corrupción, se sumó la demora en comenzar a rastrear los enfermos y la tardanza en reducir el número de pasajeros que llega al aeropuerto internacional y su posterior vigilancia una vez entran al país.

Puerto Rico en estos momentos tiene toda su economía detenida, tal vez con las cifras de desempleo más altas en toda su historia. El sistema educativo da palos a ciegas para ver como concluye el año académico y cómo comienza el siguiente. La población de Puerto Rico ya muestra sus signos de agotamiento tras más de cuarenta días confinados en un limbo mediante el cual el gobierno lo único que ha hecho es imponer unas medidas de control sanitario que exigen la disciplina y la regulación del cuerpo, a la vez que los gobernantes bailan al ritmo de la corrupción.

Notas

i La resolución presentada por el juez Henry B. Brown en Downes v Bidwall el 27 de mayo de 1901 definió el estatuto
que según consigno en 2016 la Corte Suprema de Estados Unidos, ha regido y continúa rigiendo la relación de Puerto
Rico con Estados Unidos. En su resolución de 1901 Brown definió esa relación con las siguientes palabras: 1) We are
therefore of opinion that the Island of Porto Rico is a territory appurtenant and belonging to the United States, but not a
part of the United States within the revenue clauses of the Constitution y, 2) The result of what has been said is that,
while in an international sense Porto Rico was not a foreign country, since it was subject to the sovereignty of and was
owned by the United States, it was foreign to the United States in a domestic sense, because the island had not been
incorporated into the United States, but was merely appurtenant thereto as a possession. En otras palabras, Puerto
Rico devino el primer "territorio no incorporado" en la historia de los Estados Unidos y su Tribunal Supremo creó una
nueva criatura jurídica, gobernada por el congreso bajo la Cláusula Territorial dispuesta en el artículo 4 de la
Constitución estadounidense. Bajo tales resoluciones jurídicas, los habitantes del territorio no incorporado de Puerto
Rico sólo tendrían algunos derechos constitucionales.
Downes v. Bidwell, U.S. Supreme Court, 182 U.S. 244, May 27, 1901. Recuperado de
https://supreme.justia.com/cases/federal/us/182/244/case.html ii Portal del Departamento de Salud de Puerto Rico: http://www.salud.gov.pr/Pages/coronavirus.aspx iii Visualización de datos Departamento de Salud de Puerto Rico: https://bioseguridad.maps.arcgis.com/apps/opsdashboard/index.html\#/3bfb64c9a91944bc8c41edd8ff27e6df iv Instituto de Estadísticas de Puerto Rico: https://estadisticas.pr/en/covid-19 